\title{
Aspects of Compensation Threatening the Existence of Private Practitioners
}

\author{
Gary P. Wormser* \\ Division of Infectious Diseases, New York Medical \\ College, Valhalla, NY10595, USA \\ *Corresponding author: Gary P. Wormser, Division \\ of Infectious Diseases, New York Medical College, 40 \\ Sunshine Cottage Road, Skyline Office \#2N-Fo5, Valhalla, \\ NY 10595, USA
}

Received: December 22, 2016; Accepted: J anuary 03, 2017; Published: January 05, 2017

\section{Perspective}

Physicians who are registered to provide care for Medicare patients are paid for the services provided based on the billing code that they check off. Payment is not impacted by the level of expertise of the provider, nor by the degree of experience the provider has with the diagnostic code checked off, nor by either the accuracy of the diagnosis or the outcome of the patient. Payment is also unlikely to be affected even if multiple medical issues are handled at the same visit [1]. So, a provider one day out of internship who checks off certain diagnostic and billing codes is compensated at the same rate as the physician who might have discovered the disease in question or the physician who has treated 1000 such patients with that diagnosis successfully in the past. The only variable that impacts Medicare reimbursement rates to providers, despite an identical billing code, is the geographic location of the provider. Providers in some geographic areas are paid more for the same service than providers in other geographic areas.

Justification for particular levels of service is based on rather confusing (and perhaps purposefully confusing) rules on the level of documentation that is required for the medical record [1], not on the accuracy of the diagnosis or other parameters for meeting the standard-of-care. This typically results in enormously lengthy medical records aided and abetted by Medicare's push for the use of electronic records. Electronic records can be copied and pasted rather easily leading to an increasing size and complexity of the medical record. Other features of electronic records may allow providers to check off items from long lists of negative findings, even if completely unrelated to the patient's current medical issues.

In addition, use of electronic records usually places a computer between the provider and the patient limiting the face-to-face human interactions of traditional medicine. Physicians in some instances may have access to scribes who do most of the typing for them, but this results in an additional expense for the practice. Some physicians take an alternative approach and type their notes after the patient has long departed, often late into the evening when they may have already forgotten some of the data.

Medicare is currently exploring payment approaches other than fee-for-service with the goal of improving quality and efficiency, and perhaps most importantly reducing or controlling costs [2-4]. These approaches favor large group practices, have not been validated, do not appropriately consider non-medical factors in health outcomes, potentially increase time spent administratively instead of in patient care, may expose providers to financial risks, and are yet a further threat to the existence of private practitioners [2-4].

The situation is even more unfair and, perhaps more bizarre, for providers who sign up for private insurance plans. Individual providers may be reimbursed quite differently for the exact same level of service based on the negotiated rates of reimbursement. Again this negotiated rate is likely to have nothing to do with seniority, clinical experience, or patient outcomes. Independent practitioners typically have no negotiating power and are paid at such low rates that many have been driven out of private practice [5]. Large physician groups and hospital-associated physician groups often receive much higher rates of compensation, that are greater than medicare pays, and which were successfully negotiated for an identical level of service.

It would seem that all of these issues deserve the public's attention and corrective action is urgently needed. Developing a formula to assess the practitioner's seniority and experience seems doable. A formula that also includes outcomes, while clearly desirable, will be a much more challenging task, as so many variables can affect outcome, including co-morbidities and patient compliance. Perhaps the highest priority is to address the question of whether we really want to lose our private practitioners, and instead, favor large physician networks. What advantages do the latter really provide to patients? A seemingly straight-forward solution to this critical issue is to have States enact regulations that require equal payment for equal services from commercial insurance companies, being allowed to deviate from this based only on the provider's level of experience and outcome data. Why should doctor $\mathrm{x}$ in network $\mathrm{z}$ be compensated at say a $1 / 3$ greater rate than doctor $\mathrm{y}$ who is in private practice? If male physicians were compensated at higher rates than female physicians for the same level of service, or if U.S. born physicians were compensated at higher rates than foreign born practitioners, there would be public outrage. But the current inequities are brushed off or ignored. In addition, the amount of compensation must be at a high enough level that nonprocedure oriented physician practices can remain solvent [1,5]. It is time for constructive changes.

\section{Disclosures}

Dr. Wormser reports receiving research grants from Immunetics, Inc., Institute for Systems Biology, Rarecyte, Inc., and Quidel Corporation. He owns equity in Abbott; has been an expert witness in malpractice cases involving Lyme disease; and is an unpaid board member of the American Lyme Disease Foundation.

\section{References}

1. Young RA, Bayles B, Hill JH, Kumar KA, Burge S. Family physicians' opinions 
on the primary care documentation, coding, and billing system: A qualitative study from the Residency Research Network of Texas. Fam Med. 2014; 46 378-384.

2. Wynne B. For Medicare's new approach to physician payments, big questions remain. Health Affairs. 2016; 35: 1643-1646.

3. Oberlander J, Laugesen MJ. Leap of faith - Medicare's new physician payment system. N Engl J Med. 2015; 373: 1185-1187.
4. Tanenbaum SJ. Can payment reform be social reform? The lure and liabilities of the "triple aim." J Health Polit Policy Law. 2016 E pub ahead of print.

5. Montecalvo MA. Is primary care practice sustainable? From the secretary's desk. Ann Intern Med. 2015; 163: 394-395.
J Fam Med - Volume 4 Issue 1 - 2017

ISSN : 2380-0658 | www.austinpublishinggroup.com

Wormser. (C) All rights are reserved
Citation: Wormser GP. Aspects of Compensation Threatening the Existence of Private Practitioners. J Fam Med. 2017; 4(1): 1102 